\title{
ГЛОБАЛЬНОЕ КОНКУРЕНТНОЕ ПРОСТРАНСТВО: НОВЫЕ УСЛОВИЯ, ИСТОЧНИКИ МОНОПОЛИЗАЦИИ И ВОЗМОЖНОСТИ РЕГУЛИРОВАНИЯ
}

\begin{abstract}
А.А. Праневич
Рассматриваются вопросы динамических изменений характера и форм конкурентного взаимодействия, вызванных технологическим развитием, цифровизацией, появлением новых моделей ведения бизнеса и функционированием сетевых структур. Показано, что создание новых инновационных и структурные преобразования традиционных рынков порождают принципиально новые конкурентные условия, источники монополизации, что формирует запрос на корректировку стандартных подходов к оценке рыночной власти и мерам антимонопольного регулирования. Определены возможности включения в глобальное технологическое конкурентное пространство национальной экономики и предложены меры по развитию международного сотрудничества, нацеленного на преодоление цифрового неравенства между странами, и совершенствованию в новых условиях конкурентной и антимонопольной политики Республики Беларусь.
\end{abstract}

Ключевые слова: глобальное конкурентное пространство, цифровая трансформация, цифровое неравенство, источники монополизации, цифровые платформы, сетевые эффекты, многосторонние рынки, антимонопольное регулирование.

JEL-классификация: К21, О33, О43.

DOI: $10.46782 / 1818-4510-2021-1-4-22$

Материал поступил 9.12.2020 г.

Структурные изменения в мировой экономике, новые макро- и микроэкономические явления (глобализация, распространение информационных технологий, формирование инновационных рынков, цифровизация, развитие сетевых структур) создают условия для качественных преобразований глобального экономического пространства. Изменения затрагивают:

рынки, существенно преобразуя их архитектуру, субъектно-объектные характеристики и механизмы организации рыночного взаимодействия на основе распространения модульных цифровых платформ и технологий, что приводит к исчезновению или трансформации традиционных и возникновению новых, многосторонних рынков, косвенных сетевых внешних эффектов, появлению новых и фундаментальному изменению традиционных бизнес-моделей участников рынка, созданию как новых возможностей для формирования конкурентных рынков в традиционных и новых сфеpax экономики, так и новых источников и способов ограничения конкуренции на них; производство, где конвергенция отраслей и технологий привела к трансформации форм капитала, механизма их функционирования, способов взаимодействия компаний друг с другом по всей цепочке создания добавленной стоимости, возникновению гиперконкурентных интегрированных компаний;

торговлю и международный обмен, которые вышли на новый этап своего развития в результате цифровизации, с одной стороны, ускоряя динамику в результате снижения скорости и трансакционных издержек их организации, а с другой - приводя к усилению неравенства стран (Singh, 2017), обусловленному дифференциацией доступа к цифровой инфраструктуре, возможностями организации и масштабами

* Праневич Алла Александровна (pranevich@bseu.by), доктор экономических наук, профессор, Белорусский государственный экономический университет (г. Минск, Беларусь). 
участия в цифровой торговле, зависимостью от повсеместного распространения, политического и социального влияния отдельных крупных цифровых фирм.

Глобальные экономические трансформации предопределили скорость и глубину изменений конкурентных процессов, широта охвата которых, неоднозначность и сложность воздействия на экономики стран и регионов положили начало дискуссии в экономической литературе в части:

- определения современного состояния предметной области исследования, развития методологии исследования конкурентных процессов, поскольку в условиях «новой» экономики они лишь в незначительной степени могут быть объяснены в рамках неоклассического структурного подхода;

- выявления условий и факторов модификации конкурентного пространства, опосредующих изменение форм, остроты, масштабов взаимодействия субъектов рыночной конкуренции;

- корректировки стандартных механизмов защиты конкуренции на них. Использование мер традиционного антимонопольного законодательства имеет ограничения, связанные с определением границ рынка, применимостью традиционных методов и инструментов оценки рыночной власти и установление антиконкурентного поведения, применением методов предотвращения нарушений антимонопольного законодательства;

- определения возможностей преодоления «цифрового монополизма» и цифрового неравенства стран и регионов, включения национальной экономики в мировое цифровое конкурентное пространство.

На основе выявления факторов трансформации современного глобального конкурентного пространства, источников конкурентных угроз и рисков его монополизации рассмотрим меры по их нивелированию и повышению эффективности интеграции национальной экономики в глобальное технологическое и цифровое конкурентное пространство.

\section{Методология исследования}

Характер современных хозяйственных трансформаций противоречив. С одной стороны, это движение к более открытой конкурентной рыночной среде, с другой постоянно увеличивающееся разнообразие национальных и региональных форм социально-экономических отношений, субъектно-объектные рыночные трансформации и инновационное развитие. Специфика объекта исследования, сложность процесса и поиск альтернативных подходов к его оценке осложняют выбор оптимальной теоретической платформы преобразований.

Начало исследованию инновационной конкуренции и рынков, находящихся в состоянии перманентного неравновесия, было положено в концепции творческого разрушения Й. Шумпетера ${ }^{1}$, где, в отличие от исследований рыночного равновесия, делался акцент на процессе движения рынков от равновесия и в сторону равновесия, а конкуренция характеризовалась как динамический процесс. Согласно подходу Й. Шумпетера, а позднее и представителей эволюционной экономики (Гэлбрейт, 2004; Нельсон, Уинтер, 2002), конкурентная борьба должна рассматриваться через призму взаимосвязи конкурентной среды, где выявляются институциональные факторы, позволяющие завоевать лучшие позиции хозяйствующим субъектам, и инновационной деятельности, определяющей их конкурентные преимущества, а роль государства заключается в интервенциях в динамично развивающиеся сферы экономики, характеризующиеся эффектом масштаба, быстрым развитием науки и научных исследований, техническим и технологическим прогрессом.

Оценка взаимосвязи экономического роста и инновационности, влияния на нее конкуренции, создаваемой новыми предприятиями, входящими в отрасль, была дана американским экономистом У.Дж. Баумолем (2013). Поставив под сомнение тезис либеральной экономической теории о ценовой конкуренции как основном двигателе экономического роста, он отметил наличие значительного эффекта, возникающего прежде всего в олигополистических структурах в результате сочетания предпринимательских, прорывных и текущих систематических инноваций.

${ }^{1}$ Шумпетер Й.А. 1995. Капитализм, социализм и демократия. Москва: Экономика. 
Рыночные и институциональные трансформации, приводящие к формированию двусторонних или многосторонних рынков, появлению сетевых экстерналий, стали предметом исследования теории сетей, начало которого было заложено в работах (Katz, Shapiro, 1985; Economides, 1996; Church, King, 1993). В исследованиях, относящихся к первому десятилетию XXI в., проводится более детальный анализ функционирования отдельных рынков: банковских карт (Chakravorti, Chaturvedi, 2017); журнальной продукции (Wright, 2004); особенностей ценообразования (Rochet, Tirole, 2003; Hermalin, Katz, 2006); конкурентных отношений (Armstrong, 2006; Peitz, Waldfogel, 2012), а также возможности государственного регулирования и границ применения антимонопольной (антитрестовской) политики (Evans, 2003; Rysman, 2009).

На базе теории отраслевых рынков в работах ряда американских и европейских исследователей (Caillaud, Jullien, 2003; Rochet, Tirole, 2006; Eisenmann, Parker, Van Alstyne, 2006, 2011) были заложены методологические основы изучения платформ как субъектов рынка, связывающих две или более стороны. В более поздних работах определялись особенности продуктовой дифференциации и типологизации рынков, сетевых внешних эффектов (Яблонский, 2013); прямого взаимодействия участников многостороннего рынка (Hagiu, Wright, 2011; Шаститко, Паршина, 2016).

Однако многоаспектность исследуемого процесса, специфика и скорость технологической конкуренции, появление принципиально новых типов рынка, сложность и неоднозначность оценки конкурентных процессов на них, новые экономические и социальные закономерности, порождающие масштабные институциональные преобразования, говорят о том, что системные исследования в этой области лишь только начинаются.

\section{Технологическое развитие и изменение характера конкуренции}

Процессы в современной мировой экономике, обусловленные сменой технологических укладов и сопровождаемые взрывным ростом инноваций, новых технологий, быстрым переходом экономических трансакций в цифровую среду, предопределяют изменение предмета конкуренции и природы конкурентного процесса. Ее предметом выступают интеллектуальные ресурсы и механизмы регулирования прав на них. Конкуренция принимает глобальный характер, становится более жесткой, уменьшается количество независимых субъектов, сокращается свобода конкурентной борьбы. Основными движущими силами здесь выступают:

развитие Интернет- и электронной коммерции и вызванные этим изменения в составе и предпочтениях потребителей. Построение и развитие бизнеса на основе цифровых платформ, больших данных, пулов прав интеллектуальной собственности, цифровых алгоритмов и глобализация индивидуального потребления, поддерживаемая развитием ИКТ-технологий, создают принципиально новые конкурентные условия на рынке, а также порождают новые риски монополизации и возможности субъектного доминирования в новых технологических условиях. Происходит постепенный переход от традиционной, характерной для индустриальной эпохи, ценовой конкуренции к конкуренции информационно-сетевой, меняются ее характер и условия;

развитие технологий. Следуя за технологическими новшествами, конкуренция переходит к новой, более сложной форме, или высокой технологичной стадии проявления (с использованием искусственного интеллекта), при этом сохраняя свои старые, традиционные методы конкурентной борьбы, и формируя новые, расширяя границы конкурентной борьбы и глубину ее проникновения, приводя к росту технологической зависимости и усилению межстранового неравенства, порождая проблемы, связанные с сохранением суверенитета государств и их объединений;

изменения в институциональной организации рынков, вызываемые цифровой трансформацией и появлением новых институииональных инструментов, технологических интеграторов услуг - платформ, которые оказывают существенное влияние на правила игры на них в связи с накоплением значительных массивов данных на всех 
связанных рынках. Платформы, под которыми понимаются онлайн-системы, предоставляющие комплексные типовые решения для взаимодействия пользователей, включая коммерческие транзакции, создают цифровую инфраструктуру рынков, устраняя посредников, иерархические связи и распространяя инновационные бизнес-модели; выступают архитекторами экономических систем благодаря формированию конкурентной динамики по разным звеньям глобальных цепочек создания стоимости; организуют взаимодействие пользователей так, чтобы использовать внешние сетевые эффекты, приводящие к существенному усилению рыночной власти стран и корпораций, контролирующих инфраструктуру;

изменения в конкурентном законодательстве и антимонопольном регулировании. Растущая зависимость от технологического развития определяет двойственный характер государственного регулирования. C одной стороны, государство заинтересовано в стимулировании конкуренции внутри страны для обеспечения роста занятости и общественного благосостояния, с другой в снижении конкурентного давления внешних сил. Государственная поддержка сокращает свободу конкурентной борьбы. А рост зависимости от крупного государственного или частного капитала снижает число независимых участников рынка, ведет к росту слияний и поглощений, появлению новых барьеров входа на рынок. В то же время ужесточение борьбы за «технологическую ренту» является сигналом для стран к началу разработки и установления единых для всех международных правил регулирования конкуренции.

Приоритет технологического развития определяет возрастающую потребность стран в поддержании мотивации хозяйствующих субъектов к инновациям и новым технологиям, интенсивность распространения которых является производным качества институционально-регулятивной среды. В этой связи институциональная среда становится решающим условием конкуренции на рынке, а наиболее острые ее формы перемещаются в сферы контроля над дефицитными ресурсами, позволяющими сформировать и поддерживать данную ин- ституционально-инновационную среду. Тем самым конкуренция смещается из сферы производства конечного продукта (товара, услуги) и технологической основы производства в направлении формирования институциональных преимуществ технологического развития субъектов. Конкурентная борьба за «патентный капитал» принимает масштабы гиперконкуренции, переходя между ведущими мировыми ИТ-компаниями в «патентные войны», усиливается конкуренция за новые стандарты, в которую все более втягиваются и национальные юрисдикции, их закрепляющие. Особая значимость технологических ресурсов приводит к тому, что в новой системе конкурентных отношений базовым становится противоречие между формирующимся глобальным конкурентным пространством и частными, эгоцентрическими интересами его использования отдельными странами и субъектами - обладателями монопольной власти (Зобова, Щербакова, Евдокимова, 2018).

Рост значения и стоимости знаний и технологий становится основной предпосылкой для возникновения новых технологических и цифровых рынков, обладающих качественно новыми характеристиками конкуренции, обусловленными:

- спецификой предлагаемой продукции, включая наличие правовой охраны объектов интеллектуальной собственности, что позволяет обеспечить для обладателя этих прав (пусть даже и определенный временной период) возможность получения технологической ренты;

- изменениями в рыночных ограничениях (барьерах), которые в отличие от барьеров входа на традиционных рынках определяются степенью инновационной восприимчивости предприятий и складываются из затрат на освоение и использование новой инфраструктуры и технологии;

- зависимостью спроса на инновации и интеллектуальную продукцию от спроса на конечную продукцию, при производстве которой используются данные технологии;

- использованием интеллектуальных прав в качестве инструмента конкурентного воздействия и достижения доминирующего положения; 
- взаимосвязью и взаимозависимостью внутреннего и международного рынков инновационных технологий, где ориентиры задает международный рынок, формированием глобального характера потребления успешной продукции и транснационального характера конкурентного поведения фирм (Беляков, 2015).

Конкуренция на технологических рынках приобретает динамический характер в силу: во-первых - асимметричности взаимоотношений субъектов конкуренции и множественности вариантов их выбора; вовторых - различного конкурентного потенциала участников, ориентированных на получение высокой, а не нормальной средней прибыли; в-третьих - влияния окружающей среды на поведение фирм. Динамичность развития технологий, инновационная составляющая продукции определяют склонность на таких рынках к рыночной структуре с доминирующей фирмой, формируют ситуацию, в результате которой эти рынки больше не могут конкурировать с новыми участниками и конкурентный процесс переходит от конкуренции «на рынке» к конкуренции «за рынок».

\section{Источники и угрозы современного монополизма}

В условиях формирования глобального технологического пространства и экспансии технологических фирм угроза современного монополизма состоит не в том, что монополии могут повышать цены, а в том, что они способны тормозить инновационный процесс, содействовать усилению технологического пространственного неравенства, делению стран на лидеров и периферию, росту регионализации и протекционизма на фоне усиления рыночной власти основных технологических гигантов. В силу ускорения всех рыночных процессов и снижения сроков корпоративного долголетия (для примера, в XX в. типичная компания $\mathrm{S} \& \mathrm{P} 500$ просуществовала более 60 лет, в наши дни средняя продолжительность жизни составляет всего 18 лет) процессы монополизации технологических рынков могут занимать гораздо меньше времени, чем на традиционных рынках, но иметь более разрушающее воздействие.
Основными источниками монополизации становятся: доминирование и рьночная власть, определяющие усиление позиции крупных фирм в силу возможности концентрации ресурсов, быстрого возврата затрат на НИОКР, снижения рисков невозврата вложений; территориальнье диспропорции технологчческих рынков и цифровое неравенство стран, порождающие монополистические тенденции в силу высокой затратности формирования и поддержания институциональных условий, обеспечивающих благоприятную конкурентную среду для развития инновационной деятельности.

Основой доминирования субъектов технологической конкуренции выступает устойчиво сохраняющаяся в мировой экономике социальная, имущественная и межстрановая дифференциация. Уже существующий технологический разрыв между развитыми странами - США, Японией, странами Западной Европы и развивающимися государствами многократно возрастает в результате становления цифровой экономики, формирования условий доминирования цифровых платформ. При определенном позитивном влиянии глобальных платформ на развитие международной конкуренции и выбор потребителей нельзя отрицать факт появления признаков монополизма как только платформы начинают закрепляться на своих целевых рынках. В силу скорости и непредсказуемости технологических изменений платформенные стратегии не гарантируют компаниям долгосрочную монополию сегментов рынка, но меняют характер и условия конкуренции - помимо компаний, соперничают и платформы, результатом чего становится расширение географических границ рынка, рост экспансии и доминирования инновационных фирм в глобальном масштабе. Это создает определенные угрозы для конкурентной организации, в их числе - появление сетевых эффектов, новых технологических барьеров, значимость которых определяется свойствами и параметрами используемой технологии, поведенческих барьеров, возникающих, в частности, в результате неконкурентного поведения цифровых платформ, использования ими нестандартной ценовой политики, политики стратегических погло- 
щений, что в совокупности формирует запрос на оценку необходимости и достаточности имеющихся мер и инструментов традиционного антимонопольного регулирования.

Оценка деловой практики ведущих технологических и цифровых гигантов показывает, что характер монополистической угрозы для конкурентной рыночной организации могут носить сильные сетевые внешние эффекты. Их возникновение связано, прежде всего, с нетрадиционными проявлениями таких характеристик рынка, как спрос и предложение, когда спрос на товар или услугу обусловлен не столько ценой на товар или его характеристиками, сколько его широким распространением (Яблонский, 2013). Сильные сетевые эффекты становятся мощным барьером для выхода новых фирм на рынок, вытесняют действующие и укрепляют рыночную власть. Цифровые платформы, ценность которых возрастает в разы по мере увеличения числа пользователей - как продавцов, так и покупателей, демонстрируют сильные сетевые эффекты, поскольку соединяют разрозненные сегменты рынка, а их доминирование может иметь колоссальный мультипликативный эффект.

Первой компанией, в основе рыночной власти которой лежат сильные сетевые эффекты, вытекающие из огромного количества пользователей и высоких затрат на коммутацию (ее доминирование на рынках социальных сетей и цифровой медийной рекламы стало поводом для обвинения в монополизме), является Facebook (рис. 1). Так, количество активных пользователей
Facebook за последние 10 лет по всему миру увеличилось с 608 млн чел. в 2011 г. до 2,5 млрд чел. на начало 2020 г., а средний доход от рекламы на одного пользователя за этот же период вырос с 5 долл. до 29,25 долл. США. Быстрый рост доминирования Facebook обусловлен в том числе и увеличением размера его экосистемы, продукты которого Instagram, Messenger и WhatsApp демонстрируют экспоненциальный рост пользователей, составив 3,14 млрд ежемесячных активных пользователей при среднем доходе на каждого 6,1 долл. США².

Монополия Facebook изолирована от внешних угроз, а видимость конкуренции поддерживается тем, что Facebook активно конкурирует на рынке со своими собственными продуктами (Instagram, WhatsApp и Messenger).

Неоднократной критике за препятствование конкуренции и монополизм в области интернет-торговли товарами подвергалась и Amazon, услугами которой для продвижения своих товаров пользуются 2,3 млн продавцов. По разным оценкам, Amazon контролирует около 40\% всех розничных интернет-продаж в США, для 37\% продавцов мира эта площадка является единственным источником дохода, что делает их заложниками политики IT-гиганта ${ }^{3}$.

2 URL: https://www.statista.com/statistics/277123/ internet-companies-revenue/; URL: https:// www.statista.com/ statistics $/ 264810 /$ number-of-monthly-activefacebook-usersworldwide; URL: https://www.statista.com/statistics/253577/ number-of-monthly-active-instagram-users

${ }^{3}$ URL: https://www.junglescout.com/wpcontent/uploads/ 2020/02/State-of-the-Seller-Survey.pdf

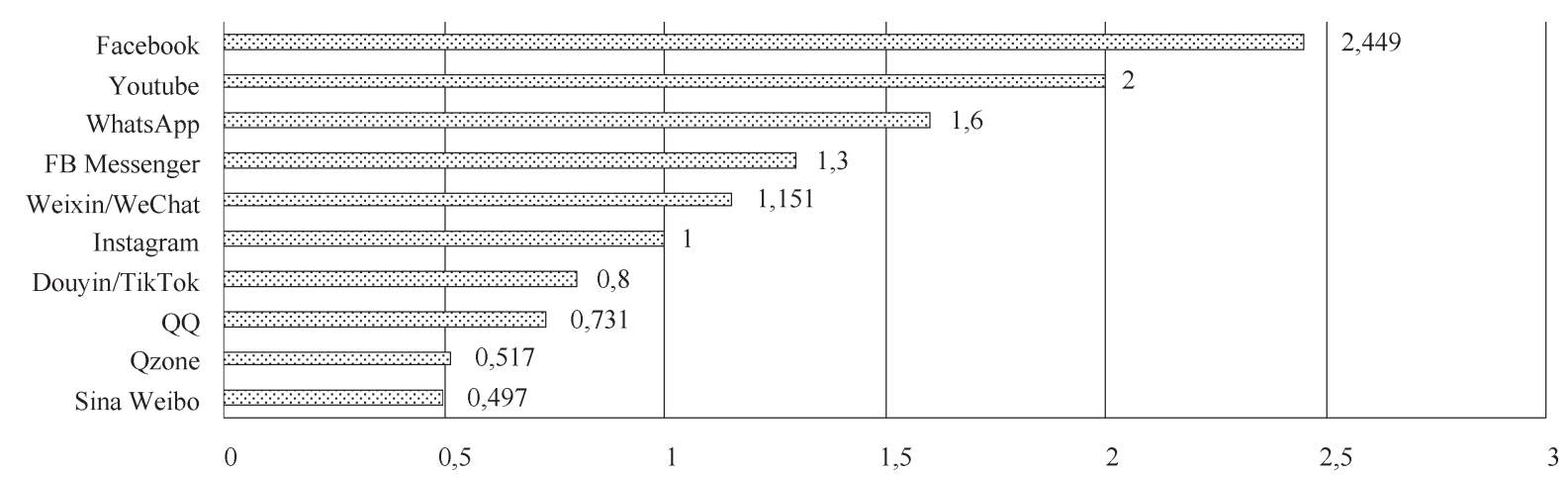

Рис. 1. Наиболее используемые социальные платформы (активные пользователи в месяц), млн чел.

Источник. URL: https:// www.statista.com/statistics/264810/number-of-monthly-activefacebook-usersworldwide 
Монопольное положение на рынке поисковых систем занимает и Google. Каждый из девяти продуктов Google - Android, Chrome, Gmail, Google Поиск, Google Drive, Google Maps, Google Photos, Google Play Store и YouTube - имеет более миллиарда пользователей ${ }^{4}$. Сервисы предоставляют Google пользовательские данные, еще более усиливая доминирование на рынках и стимулируя доходы от онлайн-рекламы, которые в 2019 г. составили 103,73 млрд долл. США, или более 83\% доходов Google 5

На сегодняшний день результатом проявления сетевых эффектов можно считать наличие фактической дуополии Google и Facebook в рекламе, усиленной к тому же их контролем над данными пользователей.

Еще одним серьезным риском монополизации является использование цифровыми платформами ресурсов больших данных в целях получения стратегических преимуществ в реализации собственной политики, схем ценовой дискриминации или предоставлении клиентских услуг. Оценка реализуемых Amazon, Apple, Facebook и Google ${ }^{6}$ бизнес-моделей позволяет выделить ряд возможностей применения ими недобросовестных антиконкурентных практик, создания своего рода новых технологических и поведенческих барьеров входа:

- использование преимуществ платформ для организации доступа на смежные рынки. Если на традиционных рынках монополист контролирует только рынок того това$\mathrm{pa}$, который он производит, то монополия цифровых платформ распространяется в том числе и на другие рынки, связанные с платформой. Доминирующая платформа может использовать рыночную власть на одном рынке в качестве аргумента-давления и способа выхода на другой, несвязанный рынок, или направление бизнеса, автоматически распространяя концентрацию с одного рынка на другие. Так, свое доминирование в онлайн-торговле использовала Amazon. Зависящие от

${ }^{4}$ URL: https://www.fastcompany.com/90380618/howgoogle-photos-joined-the-billion-user-club

${ }_{5}^{5}$ URL: https://www.emarketer.com/content/globaldigital-ad-spending-2019

6 URL: https://advocacy.consumerreports.org/wpcontent/uploads/2020/09/FINAL-CR-survey-report. platformperceptions-consumer-attitudes-.september-2020.pdf этой розничной платформы участники рынка вынуждены были принимать ее требования даже на других рынках, фактически обеспечивая Amazon возможность диктовать условия торговли;

- высокие издержки переключения для пользователей платформ, когда рыночная власть фирм определяется действующей технологией. Пользователи вынуждены оставаться на действующей платформе из-за слишком высоких затрат на переключение, что с течением времени определяет тенденцию к снижению конкуренции. Так, высокая стоимость коммутации является центральной особенностью цифровых поисковых и социальных медиаплатформ, таких как Google и Facebook, где, внеся свои данные на них, пользователи не могут их перенести на конкурирующую платформу. Высокие затраты переключения имеют место на рынке смартфонов, когда необходимость изучения новой операционной системы вынуждает потребителей оставаться либо в сфере влияния Google, либо Apple. Доминирование Apple на рынке мобильных приложений определяется ее полным контролем мобильной операционной системы $\mathrm{iOS}$, что позволяет контролировать всю дистрибуцию программного обеспечения для устройств на iOS. В результате Apple, по сути, обладает монопольной властью, контролируя доступ более чем к 100 млн айфонов и айпадов в США;

- создание закрытых экосистем, исключающих совместимость программных продуктов иных разработчиков с доминирующей платформой и/или платформами третьих лиц. Так, Google, чтобы изолировать себя от конкуренции, сохранить свою монополию как поисковой системы, вытеснить сторонних разработчиков, выдвигал для производителей смартфонов, использующих Android, обязательное требование по установке статуса по умолчанию, определенного Google apps;

- получение конкурентных преимуществ на основе сбора и использования данных пользователей, аккумулируемых на платформе. Такой стратегии придерживалась Amazon при определении лидеров продаж сторонних производителей в целях распространения их «реплик» или подражательных версий; 
- реализация технологическими гигантами и цифровыми платформами политики стратегических поглощений как политики развития, приводящей к снижению конкуренции в конкретном направлении деятельности. Так, из трех наиболее прибыльных ИТ-компаний - лидер списка Dell Technologies (США) в 2015 г. совершила одну из самых дорогих покупок в IT-индустрии, приобретя ЕМС за 67 млрд долл. США. Занимающий вторую строчку IBM (США) на протяжении своего существования провел более 130 поглощений и слияний, среди которых сделка с Red Hat стоимостью 34 млрд долл. США. Cisco Systems (США) - третья самая успешная IT-компания в мире по доходу. Начиная с 1993 г. Сisco поглотила примерно 170 разных предприятий. В 2019 г. зарегистрировано 1289 сделок по слияниям и поглощениям (M\&A) на рынке корпоративного программного обеспечения против 1241 и 1050 годом и двумя годами ранее соответственно. Общее количество M\&A-сделок на рынке ИТ- и бизнес-услуг в 2019 г. оказалось равным 787, а 43\% сделок пришлось на сегмент технологических услуг и услуг поддержки.

Преимуществом для доминирующих платформ и существенной угрозой для конкуренции выступает их возможность выявлять и «приобретать» конкурентов на ранних этапах жизненного цикла. Нехватка ресурсов и возможностей не позволяет стартапам и неплатформенным компаниям самостоятельно участвовать в конкурентной борьбе на складывающемся нишевом рынке. Доминирующие платформы, покупая их, устраняют потенциальных конкурентов до того момента, как они станут реальной угрозой, создают себе дополнительную возможность образования и развития собственной экосистемы, контроля за взаимосвязанными продуктами и еще большего укрепления доминирования. При этом такие приобретения не всегда можно определить как антиконкурентные, например, в случае покупки по цене ниже соответствующего порогового значения для рассмотрения сли-

${ }^{7}$ Online Platforms and Market Power, Part 1: The Free and Diverse Press: Hearing Before the Subcomm. on Antitrust, Commercial and Admin. Law of the H. Comm. on the Judiciary, яния ${ }^{7}$. Так, Microsoft стремилась усилить свое монопольное положение на рынке операционных систем для персональных компьютеров за счет приобретения компании Netscape; Facebook с целью предотвращения конкурентных угроз применял стратегию «захвата земель» в отношении быстрорастущих сторонних приложений или конкурентных стартапов (например, Instagram), за 20 лет компания Google приобрела более 260 компаний, а в целом число поглощений стартапов в сфере информационных технологий в мире с 2015 по 2018 г. возросло в 3,2 раза (с 45 до 144$)^{8}$.

Совокупность специфических условий, технологических и поведенческих барьеров (перечень используемых барьеров постоянно обновляется) входа на ИТ-рынки, особенностей институционально-регулятивной среды и возможностей быстрой потери конкурентных преимуществ способствует усилению технологической монополии отдельных стран и компаний и порождают еще одну проблему - рост зависимости стран технологической периферии. В результате того, что ИКТ являются ключевым ресурсом, обеспечивающим доступ к другим факторам, необходимым для обеспечения экономического роста и повышения уровня благосостояния, процессы цифровизации делают технологическое неравенство все более многомерным и приводят к формированию монополий двух типов корпоративной и страновой (новая тенденция современной конкуренции - борьба между странами, где расположены материнские компании технологических и цифровых ТНК).

В корпоративном секторе, как показывает анализ зарубежного опыта, рыночная власть может являться результатом как большой международной конкуренции, так и наличия конкурентных преимуществ в сфере материальных (объемы НИОКР, эффект масштаба) и нематериальных (патенты, базы дан-

116th Cong. (2019) [hereinafter Free and Diverse Press Hearing] https://judiciary.house.gov/legislation/hearings/onlineplatforms-and-market-power-part-1-free-and-diverse-press

${ }^{8}$ Shambaugh J., Nunn R., Breitwieser A., Liue P. 2018. The state of competition and dynamism: Facts about concentration, startups, and related policies. Brookings Institute. URL: https:// www.brookings.edu/research/the-state-of-competition-anddynamism-facts-about-concentration-start-ups-and-related-policies/ 
ных) активов. По данным рейтинга Global Tор 100, ежегодно публикуемого аудиторской сетью PricewaterhouseCoopers (PwC), современными корпоративными лидерами стали компании, создавшие успешный цифровой бизнес, тогда как компании с доступом к ресурсам теряют свои позиции. В первой десятке (2020 г.) самых дорогих компаний мира доминирует технологическая отрасль (7 компаний), а ведущие позиции занимают американские корпорации, на долю которых приходится 57 мест в рейтинге и $61 \%$ от общемирового объема рыночной стоимости (табл. 1).

Шесть компаний из первой десятки самых дорогих входят в десятку самых инновационных компаний по версии Boston Consulting Group (BCG) ${ }^{9}$.

Технологические компании из числа самых дорогих компаний мира осуществляют контроль значительной доли того или иного рынка информационных технологий. Так, рыночная власть Google обеспечена контролем 90\% мирового онлайн-поиска. Лидеры мирового ИТ-рынка по уровню доходности в 2020 г. - Dell EMC, HPE/New H3C Group и Inspur - занимают соответственно 16,7, 15,1 и 7,8\% доли серверного рынка. Опять же Dell и HPE/New H3C Group, по данным International Data Corporation (IDC), контролируют 20,6 и 18\% соответственно глобального рынка

9 Места распределились следующим образом: 1 - Apple; 2 - Alphabet; 3 - Amazon; 4 - Microsoft; 7 - Alibaba: 10 - Facebook. URL: https://www.bcg.com/ publications/2020/most-innovative-companies/data-overview корпоративных систем хранения данных. Рынок полупроводниковой продукции находится под контролем южнокорейского гиганта Samsung (15,5\%), Intel (14\%), SK Hynix (7,6\%). Практически треть рынка облачных инфраструктур (32\%), по данным компании Canalys, находится под контролем платформы Amazon Web Services (AWS). А вместе с занимающими второе Microsoft Azure (17\% рынка), третье Google Cloud (8\% рынка) и четвертое Alibaba Cloud (4\% рынка) места сообща контролируют $61 \%$ мировой отрасли облачных инфраструктур ${ }^{10}$.

Несмотря на то, что за последнее десятилетие список крупнейших мировых компаний претерпел существенные изменения (если в 2008 г. в топ-10 входила единственная платформенная компания Microsoft, то в 2020 г. - 7 (Apple, Microsoft, Amazon, Google, Facebook, Alibaba, Tencent)), их географическая и страновая локализация практически не изменилась. Ровно половина корпораций, попавших в топ-50 2020 г., базируются на территории США, $20 \%$ - компании из Азии, $30 \%$ - европейские (рис. 2).

Усиление странового монополизма связано с ростом влияния факторов специализации на создание новых технологий, организации их защиты посредством института интеллектуального и, прежде всего, патентного права; локализации субъек-

${ }^{10}$ IT-рынок в цифрах: статистика и прогнозы развития. URL: https://servernews.ru/987595

Таблица 1

Самые дорогие компании мира по данным Global Top 100, 2020 г.

\begin{tabular}{|c|c|c|c|c|}
\hline $\begin{array}{c}\text { Место } \\
\text { в рейтинге }\end{array}$ & Компания & Сектор & Страна размещения & $\begin{array}{c}\text { Стоимость, } \\
\text { трлн долл. США }\end{array}$ \\
\hline 1 & Saudi Aramco & Нефтегазовый & Саудовская Аравия & 1,602 \\
\hline 2 & Microsoft & Технологический & США & 1,200 \\
\hline 3 & Apple & Технологический & США & 1,113 \\
\hline 4 & Amazon & Онлайн-торговли & США & 0,971 \\
\hline 5 & Alphabet & Технологический & США & 0,799 \\
\hline 6 & Alibaba & Онлайн-торговли & США & 0,522 \\
\hline 7 & Facebook & Технологический & США & 0,475 \\
\hline 8 & Tencent & Технологический & Китай & 0,469 \\
\hline 9 & Berkshire Hathaway & Финансовый & США & 0,443 \\
\hline 10 & Johnson \& Johnson & $\begin{array}{c}\text { Здравоохранения } \\
\text { и биотехнологий }\end{array}$ & США & 0,346 \\
\hline
\end{tabular}

Источник. URL: https://www.pwc.ch/en/insights/digital/global-top-100-companies-2020.html 

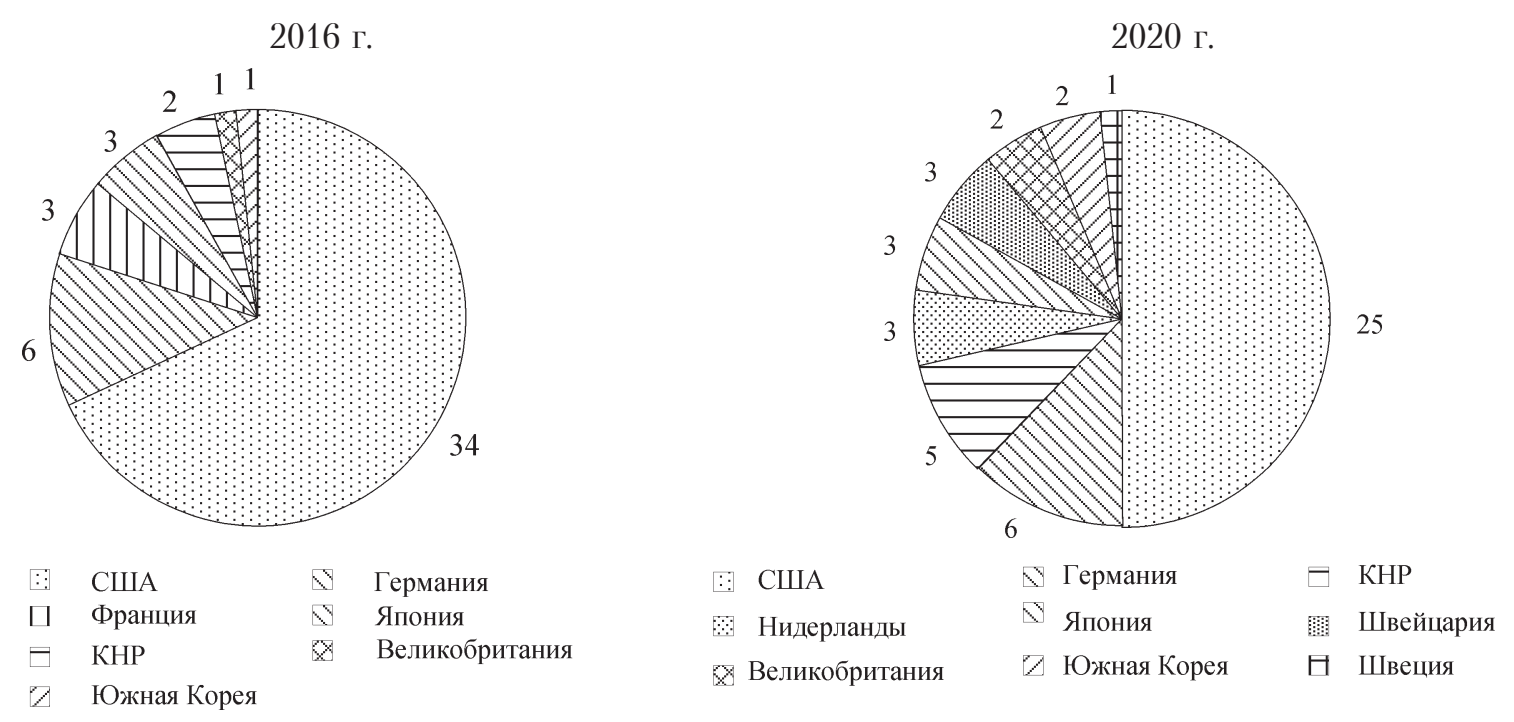

Рис. 2. Локализация 50 наиболее инновационных компаний мира, 2016 г. и 2020 г.

Источник. URL: http://www.bcg.com

тов, доминирующих в результате использования дискриминационных способов удержания конкурентных технологических преимуществ на отдельных сегментах цифровых рынков. Страны-лидеры, в числе которых Япония, США, Германия, Сингапур, Швейцария, не только вносят существенный вклад ИТ-индустрии в экономику собственных стран (например, США около $20 \%, \mathrm{EC}-17 \%$, Израиль - 11\%, Япония $10,6 \%)$, но и определяют сценарии развития отраслей и мировых рынков.

Неравномерность географии создания, распространения и использования данных приводит к появлению нового глобального разрыва - цифрового. Согласно Докладу о цифровой экономике, подготовленному Конференцией $\mathrm{OOH}$ по торговле и развитию ${ }^{11}$, в цифровой экономике не наблюдается традиционного противостояния Севера и Юга, а ведущая роль принадлежит двум странам: развитой - США и развивающейся - Китай (на долю цифровой экономики в 2019 г. пришлось более 36\% всего ВВП Китая, а китайская платформа WeChat (Tencent Holdings) показывает среди неамериканских цифровых платформ самый впечатляющий рост - в 22 раза, с 50 млн чел. в 2011 г. до 1,15 млрд чел. в 2020 г.), на долю которых приходится около 40\% добавленной стоимости, создаваемой в мировом секторе информационно-коммуникаци-

${ }^{11}$ URL: https://unctad.org/webflyer/world-investmentreport-2019 онных технологий (ИКТ), более 75\% мирового рынка открытых технологий облачных вычислений. У этих двух стран 90\% рыночной капитализации 70 крупнейших цифровых платформ мира, при достаточно скромной доле Европы - 4\% и лишь 1\% Африки и Латинской Америки ${ }^{12}$.

Неравенство ярко проявляется в экспорте товаров информационно-коммуникационного сектора. Так, у стран, занимающих лидирующие позиции, доля товаров информационно-коммуникационного сектора в общем объеме торговли находится в диапазоне от 5 до 30-35\%, тогда как в структуре экспорта у 29 стран мира составляет $0,2 \%$ и менее (рис. 3 ).

Тренд на усиление технологического и цифрового монополизма лидирующих стран и компаний оказывает существенное негативное влияние на страны технологической периферии на уровне:

- отдельных рынков. Так, контроль 74\% мирового рынка промышленной робототехники осуществляют пять стран - КНР, Япония, Германия, США и Южная Корея. Согласно отчету Derwent Top 100 Global Innovators 2020, США и Япония контролируют 71\% патентного рынка. На долю семи «суперплатформ» (Apple, Microsoft, Amazon, Google, Facebook, Alibaba, Tencent) приходится две трети совокупной капитализации цифрового рынка;

\footnotetext{
${ }^{12}$ URL: http://www.unctad.org
} 


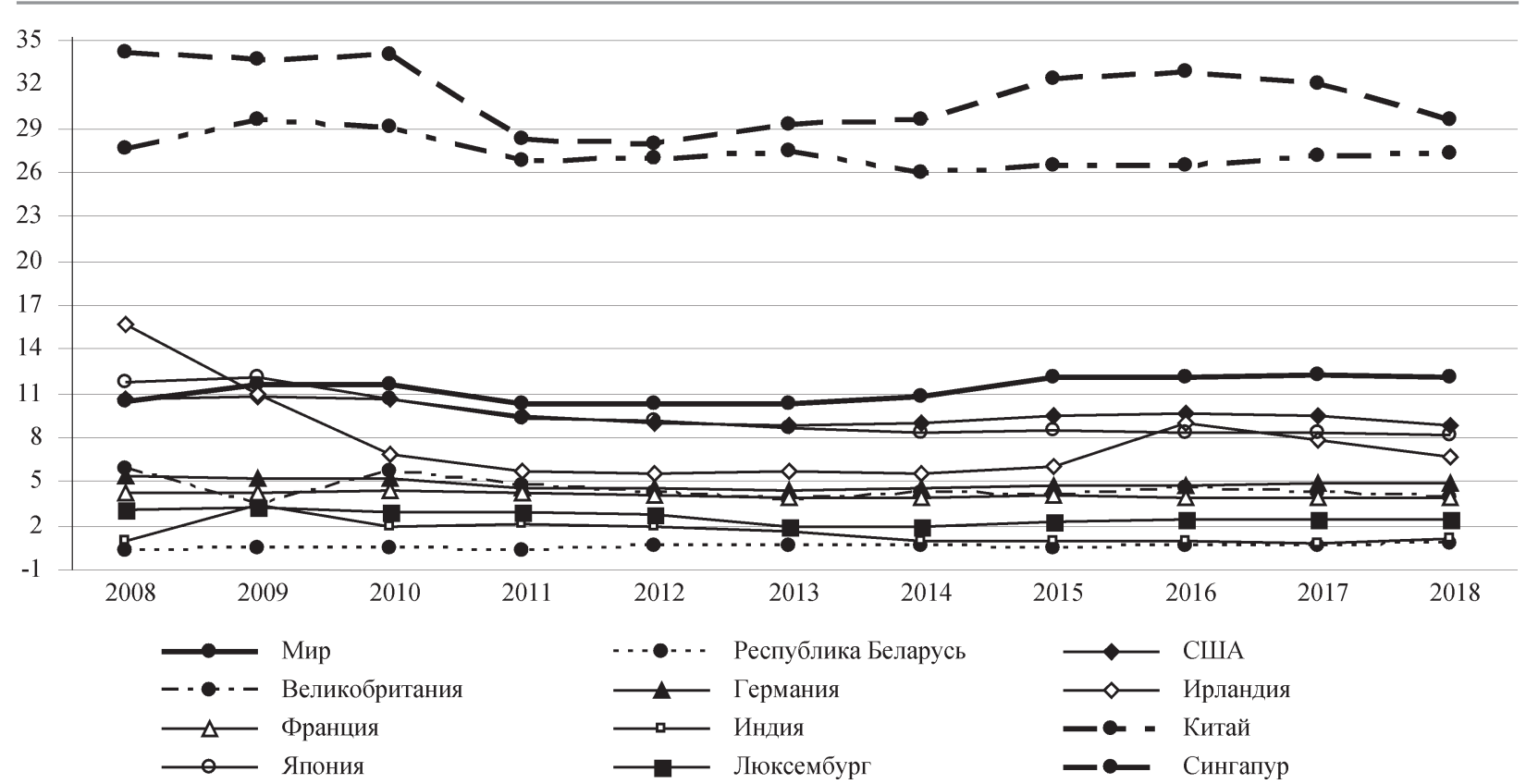

Рис. 3. Доля товаров ИКТ в общем объеме торговли, \% в год

Источник. Авторская разработка на основе: URL: http://www.unctad.org

- глобальных цепочек создания стоимости в цифровой среде, потенциально вызывая эффект, аналогичный эффекту ВанекаРайнерта. Так, как правило, развивающиеся страны включаются в цепочки добавленной стоимости в деятельности с уменьшающейся отдачей. Этот факт, а также устранение барьеров на пути функционирования глобальных цифровых лидеров на внутренних рынках развивающихся стран может явиться причиной потери конкурентоспособности для национальных компаний, а в длительной перспективе для технологических секторов и национальной экономики в целом;

- усиления технологической зависимости, связанной, с одной стороны, с опорой в своей политике технологических изменений на производственные технологии, находящиеся на последней стадии жизненного цикла (что ведет к быстрой деградации собственных возможностей, росту угроз цифровизации), а с другой - с захватом национальных рынков мощными транснациональными компаниями ${ }^{13}$;

- появления сильной мотивации к изменению регулирования в области интеллектуальной собственности, конкурентной,

${ }_{13}$ Касперская Н. 2018. Цифровая экономика и риски иифровой колонизаиии: развернутые тезисы выступления на Парламентских слушаниях в Госдуме. URL: https:// cont.ws/@sage/884423 антимонопольной, промышленной и инновационной политики. Негативный эффект усиливается тем фактом, что мировые регулятивные стандарты в основном были разработаны в соответствии с интересами развитых экономик и слабо учитывают интересы развивающихся государств.

Однако неравенство стран не является следствием линейных социальных процессов. Технологические и цифровые преференции лидеров имеют ограничения, поэтому для развивающихся стран существуют возможности преодоления географических и страновых контрастов путем реализации программ технологического и цифрового развития для ускорения темпов своего роста, минуя целые этапы процесса технологической и цифровой модернизации, определяя собственный выбор между стимулирующим воздействием конкуренции на эффективность и необходимостью принятия некоторых защитных мер для национальных рынков.

\section{Антимонопольное регулирование: возможности и ограничения выбора между конкуренцией, эффективностью и инновациями}

Роль и степень участия государства в устранении проблем, связанных с несостоятельностью рынка в ИКТ-сегментах, до 
конца четко не определены. Главной проблемой для регулирования конкурентных процессов в условиях роста влияния технологических и цифровых монополий выступает необходимость формирования таких институциональных условий, которые бы, с одной стороны, способствовали минимизации рисков неэкономического характера и «провалов рынка», а с другой, не препятствовали технологическому развитию стран, регионов и восприятию инноваций субъектами рынка.

Несмотря на то, что в мировой экономике имеется достаточно стройная система антимонопольного регулирования, цифровая трансформация показывает определенную ограниченность применения инструментов и мер традиционного конкурентного права, и прежде всего:

- в использовании методов ценовой конкуренции. В традиционной экономике основным показателем для реализации мер антимонопольной политики выступает снижение благосостояния потребителя в результате ценовой дискриминации. На цифровых рынках ориентир на него имеет, по крайней мере, два ограничения. Во-первых, цифровые платформы, как основные субъекты цифровой экономики, часто используют ценообразование для расширения своей деятельности. Суть реализации такой стратегии состоит в монополизации рынка (сетевой торговой площадки) через кратковременное снижение цен на предлагаемый товар, конечной целью которого становится вытеснение главного конкурента с рынка. Однако первоначальное снижение цены не является сигналом для применения мер антимонопольного регулирования, ибо соответствует критерию роста благосостояния потребителя. Во-вторых, в отличие от традиционной экономики, действующие хозяйствующие субъекты в цифровой среде ориентированы не на максимизацию прибыли через рост цен, а на реализацию стратегии увеличения доли рынка или диверсификации, поэтому для конечного потребителя цены могут даже снижаться.

Таким образом, использование методов ценовой конкуренции в цифровой экономике для применения мер антимонопольного регулирования не является сигнальным (Shelanski, 2013), во-первых, потому, что в силу быстрых, а порой и стремительных, колебаний цен их анализ и оценка воздействия на благосостояние потребителей часто не представляются возможными; а вовторых, потребители часто получают услуги в обмен на информацию по номинальным нулевым ценам;

- при определении географических или продуктовых границ рынков для цифровых компаний. Поскольку платформа на цифровом рынке выступает в роли поставщика промежуточного продукта, идентифицировать спрос и предложение на который практически не представляется возможным, традиционное определение рынка по отношению к товару или услуге применить нельзя. Это подразумевает, что невозможно: а) оценить монопольную власть той или иной платформы с точки зрения повышения цен выше или ниже конкурентоспособного уровня; б) применить традиционный подход на основе доли субъекта на рынке к определению доминирующего положения фирмы. В последнем случае платформа выступает в роли соединительного звена между продавцом и покупателем, снижая издержки, изменяя способы монетизации и, несмотря на небольшую долю на рынке, определяя правила игры на нем. Используя ресурсы «больших данных», они имеют стратегические преимущества в реализации собственной политики, например, при разработке схемы ценовой дискриминации или в предоставлении клиентских услуг, например, в случае размещения рекламы.

В такой ситуации антимонопольным органам для применения мер антимонопольного регулирования сложно провести анализ рынка на основе оценки количественных показателей. Решение данной проблемы видится в разработке новых критериев для определения доминирующей позиции фирм на цифровых рынках, осуществлении перехода от использования преимущественно количественных критериев к анализу его качественных характеристик, таких как владение инфраструктурой, наличие барьеров входа, альтернативных путей доступа к конечным пользователям, сетевых эффектов, размер и уровень инноваций, используемых в технологиях и услугах. 
Некоторые меры для разрешения возникающих проблем в области конкурентного права в ряде стран уже применяются. Среди них:

введение ограничений в сфере бизнеса. Так, для поощрения конкуренции и предотвращения ограничительной практики со стороны онлайн-платформ, таких как Amazon и Flipkart, правительство Индии в 2018 г. ввело новые правила электронной коммерции, в соответствии с одним из которых вводится запрет платформам электронной торговли продавать продукцию компаний, в которых они имеют долю участия; контроль над сделками по слияниям и поглощениям прежде всего в случаях приобретения глобальными платформенными компаниями успешных стартапов, которые, несмотря на высокую стоимость, не всегда достигают пороговых значений. Так, в Германии Девятой реформой закона о защите конкуренции («9.GWB-Nowelle») были определены подход и критерии в отношении многосторонних рынков и сетей, введен новый порог относительно требования уведомления о контроле за слияниями. В дополнение к пороговым значениям мирового и внутреннего оборота теперь контролю подлежат сделки слияний, если цена покупки и принятые обязательства составляют более 400 млн евро;

штрафные санкции за установленные антиконкурентные действия. Так, еще в 2008 г. Евросоюз оштрафовал Microsoft на 1 млрд долл. США за нарушения антимонопольного законодательства. За «злоупотребление своим доминированием на рынке и нарушение условий конкуренции при помощи своей поисковой системы» в 2017 г. Комиссия ЕС оштрафовала компанию Google на 2,42 млрд евро ${ }^{14}$, а в общей сложности Google выплатил в Европе за последние три года порядка 9 млрд долл. США штрафов. Кроме того, в 2017 г. ЕС наложил на Facebook штраф в 122 млн долл. за нарушения, допущенные в связи с приобретением WhatsApp. В 2020 г. Совет по вопросам конкуренции Турции выставил штраф американской корпорации Google на 196,7 млн турецких лир (25,6 млн долл.

14 URL: http://europa.eu/rapid/press-release STATEMENT-17-1806_en.htm
США) за злоупотребление своим положением на рынке поисковых систем (нарушение закона Турции «О защите конкуренции»);

структурное разделение, которое не позволило бы платформе управлять бизнесом, зависящем или пересекающемся с самой этой платформой. Такой подход впервые применен на традиционном рынке в 1911 г., когда компания Standard Oil была разделена на части, а одним из инструментов стала организация совместных предприятий. В октябре 2020 г. в Конгрессе США представили доклад, составленный по итогам годичного расследования в отношении высокотехнологичных компаний с критикой злоупотребления их своим положением на рынке. В качестве выхода из сложившейся ситуации авторы доклада предложили принудительно разделить эти компании, ограничив их власть путем принятия соответствующих поправок к антимонопольному законодательству США и ввести для них ограничения на поглощение других компаний ${ }^{15}$;

меры по локализации в рамках реализации развивающимися странами политики цифрового суверенитета. Они способствуют продвижению национальных возможностей и защите молодых отраслей, предотвращению растущей зависимости от зарубежной цифровой инфраструктуры. Кроме того, требования по расположению серверов и вычислительных средств в национальных границах направлены на стимулирование иностранных инвестиций в национальную инфраструктуру. Такие требования действуют во Вьетнаме, на Филиппинах, в Индонезии.

Оценка зарубежного опыта антимонопольного регулирования в новых конкурентных условиях показывает необходимость: a) укрепления национальных механизмов политики в области конкуренции; б) формирования единых «правил игры» для всех участников экономических отношений глобальной экономики, включая унификацию институтов и инструментов воздействия на конкурентное пространство в силу глобализации инфраструктуры и складывающегося

\footnotetext{
15 URL: http: // www.expert.ru>2020/10/9/kongress/
} 
транснационального характера производственных отношений и конкурентного поведения; в) более полного использования конкурентного потенциала «емких рынков», формируемых в результате региональной интеграции и расширения многостороннего сотрудничества; г) разработки трансграничных механизмов регулирования, так как технологическая и цифровая трансформации создают условия экономического роста в силу их кроссплатформенного и трансграничного характера.

Такие механизмы, в числе которых, например, политика и правила в области электронной торговли, конкуренции и защиты прав потребителей, с одной стороны, могут обеспечить более масштабные рынки для национальных компаний и, соответственно, стимулировать рост внутрирегиональной торговли, а с другой - обеспечить более высокую, чем на национальном уровне, эффективность таких мер в борьбе со слияниями и поглощениями в ИТ-сфере, другими антиконкурентными практиками глобальных лидеров.

Использование конкурентного потенциала регионализации для обеспечения роста конкурентоспособности экономического пространства через цифровую трансформацию является приоритетом и для Европейского союза. Как уже отмечалось выше, ЕС пока отстает от Китая и США по инновационным НИОКР, только каждая десятая компания стран Союза (по данным 2018 г.) использовала технологию больших данных, каждая четвёртая - облачные вычисления, растет зависимость Европы от иностранных, прежде всего китайских, технологических компаний, а на долю объединенной Европы приходится лишь 4\% рыночной капитализации 70 крупнейших цифровых платформ мира ${ }^{16}$.

Поэтому в новой Промышленной стратегии ЕС, принятой 10.03.2020 г., предложены, с одной стороны, меры стимулирования технологического развития за счет индустриального сектора в условиях «двойного перехода» (экологической и цифровой трансформации), основанного на суверенитете, создании промышленных экосистем, новых

16 Доклад о цифровой экономике. 2019. UNCTAD. URL: https://unctad.org/system/files/official-document/ der2019_overview_ru.pdf альянсов, прорывных технологий, усилении роли малого и среднего бизнеса, а также устранении существующих препятствий для бизнеса на едином внутреннем рынке. А с другой стороны, содержится комплекс защитных мер рынков ЕС от «нежелательных» иностранных инвесторов и участников, например китайского Huawei, американских Google и Apple, получающих государственную поддержку, а следовательно, нерыночные конкурентные преимущества. Конкретные защитные меры планируется подготовить к 2021 г., которые будут прописаны в «Белой книге инструментов против иностранного субсидирования» ${ }^{17}$.

ЕАЭС также является важным рынком для глобальных цифровых компаний, на который экстраполируются их модели поведения и бизнес-практики, в том числе ограничительные. Поэтому для интеграционного союза одной из важнейших задач становится формирование уникальной модели контроля рынка, включающей расширение механизмов адвокатирования конкуренции, внедрение гибких инструментов конкурентного регулирования, чтобы, с одной стороны, сформировать механизмы пресечения цифровой монополизации рынков, а с другой - создать условия для совместного использования цифровых платформ как в целях развития национальных экономик, так и экономической экспансии субъектов ЕАЭС (Цариковский, Иванов, Войниканис, 2018. С. 110).

Положительно оценивая интеграционные возможности развития технологических и цифровых рынков, следует отметить существенные различия в экономическом потенциале стран - участниц ЕАЭС, в частности экономическое, технологическое и цифровое преобладание Российской Федерации, что является сдерживающим фактором реализации конкурентного взаимодействия.

Россия смогла снизить риски доминирования иностранных технологических гигантов - платформенных компаний, с которыми сталкиваются практически все развивающиеся страны, и сохранить конкурентную динамику на цифровых рынках. Этому способствует наблюдаемая на рынке цифровых платформ интенсивная кон-

${ }^{17}$ URL: http: // www.eurointegration.com.ua 
куренция как между российскими компаниями (Яндекс, Мэйл.ру, Озон и др.), так и зарубежными (AliExpress, Google, Facebook и др.). Российские компании, как Яндекс и Мэйл.ру, показывают рост по основным показателям (рыночная капитализация, количество пользователей, выручка), успешно (интенсивно) конкурируют с такими гигантами, как Google и Facebook, оказывают положительное влияние на российскую экономику, достигнув показателя в 1\% ВВП (Eferin, Hohlov, Rossotto, 2019). Имеющая место активная конкуренция между зарубежными и российскими цифровыми гигантами стимулирует последние к дальнейшему развитию и инновациям для увеличения клиентской базы и росту рыночной капитализации. А сохраняющиеся конкурентные вызовы со стороны крупных международных платформ, таких как YouTube, Instagram и WhatsApp, стимулируют российские платформенные компании развивать новые услуги по созданию стоимости, расширять их охват, в том числе за счет экономического пространства ЕАЭС.

Возможности единого технологического и цифрового пространства ЕАЭС несут в себе значительный потенциал для развития и роста конкурентоспособности Республики Беларусь. Национальный ИКТ-сектор показывает определенную динамику. Так, если в 2016 г. валовая добавленная стоимость деятельности 2,3 тыс. организаций ИТ-отрасли составляла 5,2\% ВДС по экономике в целом и 3\% к ВВП, то в 2019 г. соответствующие показатели 3,4 тыс. предприятий составили 7,6 и 6,6\%. При этом доля товаров сферы ИКТ в общем объеме экспорта товаров практически не изменяется - менее $1 \%$, тогда как доля услуг сферы ИКТ в общем объеме экспорта услуг имеет устойчивую тенденцию роста, с 10\% в 2013 г. до 21,4\% по итогам 2019 г. По доходам от экспорта IT-услуг Беларусь, по данным журнала Forbes, находится в одной группе стран с Индией, а также опережает Российскую Федерацию и Украину. Несомненные положительные результаты связаны с развитием Парка высоких технологий, 91\% производимого программного обеспечения которого идет на экспорт, а мобильными приложениями, разработанны- ми компаниями - резидентами ПВТ, пользуются более 1 млрд чел. в 193 странах мира ${ }^{18}$.

Следует отметить, что с позиции развития ИКТ-инфраструктуры и вовлечения населения и организаций (connectivity) Беларусь продвинулась вперед, а по показателю «создание мобильного приложения» даже вышла в лидеры. Однако проблема в том, что национальный экспорт охватывает только отдельные ниши в сфере базовых ИКТ, а относительно эффективного использования ИКТ национальная экономика значительно уступает странам-лидерам по таким важным компонентам, как «качество регулирования» и «верховенство закона», «кредитование» и «сделки с венчурным капиталом», «расходы на компьютерное программное обеспечение» и «глобальная ценность бренда» ${ }^{19}$.

Необходимость их преодоления в условиях ограниченности ресурсов определяет зависимость долгосрочного технологического и цифрового развития Республики Беларусь не столько от внутренних факторов роста, сколько от использования потенциала интеграционного взаимодействия в данной области как по линии ЕАЭС, так и в рамках трехстороннего сотрудничества и реализации модели «интеграция интеграций».

Развитие цифровой экономики государствами - членами ЕАЭС регулярно сталкивается с возникающими проблемами как на глобальном, региональном, так и на национальном уровне. Среди них высокая цифровая импортозависимость экономик стран ЕАЭС, низкая доля участия стран в международной конкуренции по созданию добавленной стоимости в цифровой экономике и низкая доля товаров ИКТ в экспорте, низкая степень коммерциализации (доступ к патентам и лицензиям) и защиты интеллектуальной собственности (Праневич, 2019).

Для ЕАЭС смена технологических укладов создает возможности для качественного роста национальных экономик странучастниц, а также предъявляет новые требо-

${ }^{18}$ Информационное общество в Республике Беларусь: стат. сборник. 2019. Минск: Национальный статистический комитет Республики Беларусь.

${ }_{19}$ The Global Innovation Index (GII) 2020: Who Will Finance Innovation? URL: https://www.globalinno vationindex.org/Home 
вания к оценке уровня конкурентной устойчивости в контексте перехода к цифровому этапу развития мировой экономики. Решение этих задач связывается с формированием единого конкурентного цифрового пространства ЕАЭС, институциональные рамки создания которого направлены на формирование конкурентоспособной цифровой региональной экономики и предполагают реализацию стимулирующих мер. В то же время характер и сила сетевых экстерналий на многосторонних рынках цифровых платформ требуют реализации мер сдерживающего (протекционистского) характера для пресечения антиконкурентных последствий конкретных действий мировых технологических и цифровых гигантов. В числе стимулирующих назовем меры по:

- гармонизации законодательства членов ЕАЭС в цифровой среде (нормативное закрепление сущностных характеристик и понятия цифровой экономики, принципов ее реализации, изменение технических регламентов в части адаптации форм оценки соответствия задачам цифровой экономики; создание общей цифровой среды доверия на пространстве ЕАЭС, а также общей политики по формированию такой среды с третьими странами и другими интеграционными объединениями);

- обеспечению правовой охраны и защиты прав на результаты интеллектуальной деятельности;

- включению национальных предприятий в глобальные цепочки создания стоимости высокотехнологичной продукции и переходу в области мер промышленной политики от национального протекционизма в сторону надгосударственного протекционизма формирующихся цепочек с целью увеличения доли добавленной стоимости, присваиваемой компаниями ЕАЭС;

- разработке механизмов импортозамещения и поддержки высокотехнологичных компаний государств - членов Союза, работающих в сфере оборота данных, а также механизмов поддержки пользователей таких компаний (по опыту ЕC);

- адаптации антимонопольного законодательства и мер защиты конкуренции к условиям цифровой экономики (формирование в части доступа к ключевым технологиям, базам данных инструментов снятия барьеров входа на рынки для «стартапов»).

К протекционистским мерам, призванным сдерживать процессы монополизации и повысить эффективность применения антимонопольного регулирования, следует отнести пересмотр законодательных подходов к понятию монополиста на товарном рынке, определению инструментов для оценки возможных антиконкурентных эффектов их поведения на технологических и цифровых рынках; внедрение правового инструментария противодействия картелям, основанного на цифровых алгоритмах, злоупотреблениям цифровыми технологиями; разработку новых критериев «доминирующего положения» на рынке интернет-пространства в направлении снижения роли количественного критерия доминирования при оценке рыночной власти компаний, смещения акцента анализа рынка для применения мер антимонопольного регулирования в сторону качественных характеристик (владение инфраструктурой, наличие барьеров входа, альтернативных путей доступа к конечным пользователям, сетевых эффектов, размер и уровень инноваций, используемых в технологиях и услугах), позволяющих хозяйствующим субъектам получать конкурентные преимущества при реализации их бизнес-стратегий; внедрение механизмов контроля за действиями владельцев цифровых платформ и доступа к данным на рынках, наиболее подверженных риску ограничения конкуренции.

Позитивными эффектами принятия и реализации предложенных мер, создания единого конкурентного цифрового пространства ЕАЭС могут стать:

организация (на основе принципов взаимного признания и интероперабельности) конкуренции между регуляторными режимами государств - членов ЕАЭС, что, с одной стороны, будет являться стимулом к совершенствованию правовых режимов государств-членов в интересах участников оборота данных, с другой - возможностью для участников рынка свободно выбирать для своего бизнеса то государство - член ЕАЭС, которое обеспечивает наиболее подходящий для данного бизнеса правовой режим; 
разработка общих механизмов защиты прав участников оборота данных в Союзе; объединение усилий стран - членов ЕАЭС по созданию платформенных компаний, экосистем цифровой экономики, развитию новых услуг по созданию стоимости и расширению их охвата за счет формирования емкого конкурентного рынка с единым регуляторным режимом.

Смена технологической парадигмы экономического развития одновременно несет в себе характеристики как «структурных изменений», кардинальным образом меняя механизм функционирования и регулирования традиционных рынков, создавая новые продукты, услуги, бизнес-модели, так и «творческого разрушения», уничтожая традиционные рынки и даже целые отрасли. Подрывная природа многих инноваций и рост крупных технологических фирм (таких как Google, Facebook, Apple, Amazon и др.), которые управляют многими из этих разработок, ставят вопрос о том, способна ли действующая система защиты конкуренции справляться с вызовами или же она нуждается в новых подходах и инструментах, определяющих выбор между конкуренцией, эффективностью и инновациями.

К основным конкурентным вызовам технологического развития можно отнести следующие:

появление новых рынков, являющихся результатом инноваций, в том числе разрушающих, где использование мер антимонопольного регулирования, основанного на анализе рынков и определении характера рыночных связей, не учитывающих постоянных циклов таких изменений, может привести к снижению эффективности их функционирования;

усиление тенденции к монополизации рынков и ограничению конкуренции в результате появления сетевых эффектов, которые могут являться барьером входа на рынок;

рост цифрового неравенства стран, связанный с их дифференциацией по доступу к цифровой инфраструктуре, возможностями организации цифровой торговли; рост неконтролируемого влияния цифровых платформ на компании-клиентов, имеющих основу для односторонних действий и координации деятельности, использования методов ценовой дискриминации.

Положительная динамика в преодолении конкурентных вызовов технологического развития связывается с изменением роли государств в современном глобальном конкурентном пространстве, построением уникальной модели контроля технологических и цифровых рынков, созданием конкурентоспособных национальных цифровых инфраструктур и экосистем, повышением эффективности инновационной политики, формированием институциональных условий для расширения регионального и многостороннего технологического сотрудничества для их преодоления.

\section{СПИСОК ЛИТЕРАТУРЫ (REFERENCES)}

Баумоль У. 2013. Микротеория инновационного предпринимательства. Москва: Издательство Института Гайдара. 420 c. [Baumol W. 2013. The microtheory of innovative entrepreneurship. Moscow: Izdatel'stvo Instituta Gaydara. 420 p. (In Russ.)]

Беляков Р.А. 2015. Экономическая сущность и функции рынка инновационных технологий. Фундаментальные исследования. № 6-1. С. 95-98. [Belyakov R.A. 2015. Economic essence and functions of market innovative technologies. Fundamental'nye issledovaniya. No 6-1. PP. 95-98. (In Russ.)]

Гелбрейт Дж.К. 2004. Новое индустриальное общество. Центр гуманитарных технологий. URL: https://gtmarket.ru/laboratory/basis/ 5021 [Galbraith J. 2004. New industrial society. Tsentr gumanitarnykh tekhnologiy. URL: https:// gtmarket.ru/laboratory/basis/5021 (In Russ.)]

Зобова Л.Л., Щербакова Л.Н., Евдокимова Е.К. 2018. Цифровая пространственная конкуренция в глобальном информационном пространстве. Фундаментальные исследования. № 5. С. 6468. [Zobova L.L., Shcherbakova L.N., Evdokimova E.K. 2018. Digital spatial competition in the global information space. Fudamental'nye issledovaniya. No 5. PP. 64-68. (In Russ.)]

Нельсон Р., Уинтер С. 2002. Эволющионная теория экономических изменений. Москва: Дело. 536 c. [Nelson R. Winter S. 2002. An evolutionary theory of economic change. Moscow: Delo. 536 p. (In Russ.)]

Праневич А.А. 2019. Трансформация конкурентной среды в условиях развития цифровой экономики: факторы модификации и возможности. Научные труды БГЭУ. Минск: Белорусский госу- 
дарственный экономический университет. С. 359364. [Pranevich A.A. 2019. The competitive environment transformation in the digital economy: Modification factors and regulatory options. Nauchnye trudy BGEU. Minsk: Belorusskiy gosudarstvennyy ekonomicheskiy universitet. (In Russ.)]

Цариковский А.Ю., Иванов А.Ю., Войниканис Е.А. (Ред.). 2018. Антимонопольное регулирование в цифровую эпоху. Как защищать конкурениию в условиях глобализации и четвертой промышленной револющии. Москва: Издательский дом Высшей школы экономики. [Tsarikovsky A.Yu., Ivanov A.Yu., Voinikanis E.A. (Eds.) Antitrust regulation in the digital age. How to protect competition in the face of globalization and the fourth industrial revolution. Moscow: Izdatel'skiy dom Vysshey shkoly ekonomiki. (In Russ.)]

Шаститко А.Е., Паршина Е.Н. 2016. Рынки с двусторонними сетевыми эффектами: спецификация предметной области. Современная конкурениия. T. 10. № 1. C. 5-18. [Shastitko A.E., Parshina E.N. 2016. Two-sided markets: The subject matter specification. Sovremennaya konkurentsiya.Vol. 10. No 1. PP. 5-18. (In Russ.)]

Яблонский C.A. 2013. Многосторонние платформы и рынки: основные подходы, концепции и практики. Российский журнал менеджмента. Т. 11. № 4. C. 57-78. [Yablonsky S.A. 2013. Multilateral platforms and markets: key approaches, concepts and practices. Rossiyskiy zhumal menedzhmenta. Vol. 11. No 4. PP. 57-78. (In Russ.)]

Armstrong M. 2006. Competition in two-sided markets. The Rand Journal of Economics. Vol. 37. Iss. 3. PP. 668-691.

Caillaud B., Jullien B. 2003. Chicken and egg: competition among intermediation service providers. The Rand Journal of Economics. Vol. 34. No 2. PP. 309-328.

Chakravorti S., Chaturvedi R. 2017. Digital planet 2017: How competitiveness and trust in digital economies vary across the world. Medford: The Fletcher School, Tufts University. 147 p.

Church J., King I. 1993. Bilingualism and network externalities. Canadian Journal of Economics. Vol. 26. No 2. PP. 337-345.

Economides N. 1996. The economics of networks. International Journal of Industrial Organization. No 14. PP. 673-699.
Eferin Y., Rossotto C., Hohlov Y. 2019. Digital platforms in Russia: competition between national and foreign multi-sided platforms stimulates growth and innovation. Digital Policy, Regulation and Governance. Vol. 21. Iss. 2. PP. 129-145.

Eisenmann T., Parker G., Van Alstyne M. 2006. Strategies for two-sided markets. Harvard Business Review. Vol. 84. Iss. 10. PP. 92-101.

Eisenmann T., Parker G., Van Alstyne M. 2011. Platform envelopment. Strategic Management Journal. Vol. 32. Iss. 12. PP. 1270-1285.

Evans D.S. 2003. Some empirical aspects of multi-sided platform industries. Review of Network Economics. Vol. 2. Iss. 3. PP. 191-209.

Hagiu A., Wright J. 2011. Multi-Sided Platforms. Harvard Business School Working Paper. No 12-024.

Hermalin B.E., Katz M. 2006. Your network or mine? The economics of routing rules. Rand Journal of Economics. Vol. 37. Iss. 3. PP. 692-719.

Katz M., Shapiro C. 1985. Network externalities, competition, and compatibility. American Economic Review. Vol. 75. No 3. PP. 424-440.

Peitz M., Waldfogel J. (Eds.). 2012. The Oxford Handbook of the Digital Economy. Oxford: Oxford University Press.

Rochet J.-C., Tirole J. 2003. Platform competition in two-sided markets. Journal of European Economic Association. Vol. 1. No 4. PP. 990-1029.

Rochet J.-C., Tirole J. 2006. Two-sided markets: An overview. RAND Journal of Economics. Vol. 35. No 3. PP. 645-667.

Rysman M. 2009. The economics of two-sided markets. Journal of Economic Perspectives. Vol. 23. No 3. PP. 125-143.

Shelanski H.A. 2013. Information, Innovation, and Competition Policy for the Internet. University of Pennsylvania Law Review. Vol. 161. No 6. PP. 1663-1705.

Singh P.J. 2017. Digital industrialisation in developing countries. A review of the business and policy landscape. URL: http://www.itforchange.net/ sites/default/files/1468/digital_industrialisation_ in_developing_countries.pdf

Wright J. 2004. One-sided logic in two-sided markets. Review of Network Economics. Vol. 3. Iss.1. PP. 42-63. 
In citation: Belorusskiy Ekonomicheskiy zhurnal. 2021. No 1. PP. 4-22

Belarusian Economic Journal. 2021. No 1. PP. 4-22.

\title{
GLOBAL COMPETITIVE SPACE: NEW CONTEXT, MONOPOLIZING SOURCES AND REGULATION OPPORTUNITIES
}

\author{
Alla Pranevich ${ }^{1}$ \\ Author affiliation: ${ }^{1}$ Belarussian State Economic University (Minsk, Belarus). \\ Corresponding author. Alla Pranevich (pranevich@bseu.by).
}

ABSTRACT. The article deals with dynamic changes of competitive interaction in nature and forms provoked by technological development, digitalization, emerging business models and functioning of network structures. The study makes it clear that creation of emerging innovative market as well as structural transformation of a traditional one engenders brand new competitive conditions and monopolizing sources. All considered forms a request to correct current approach to market power assessment and antimonopoly regulation measures. Possibilities for national economy to enter global technological competitive space are defined. Measures to develop international cooperation are suggested, what aims at addressing digital inequality among countries and advancement of competitive and antimonopoly policy in the Republic of Belarus.

KEYWORDS: global competitive space, digital transformation, digital inequality, monopolizing sources, digital platforms, network effects, multilateral markets, antimonopoly regulation.

JEL-code: K21, O33, O43.

DOI: $10.46782 / 1818-4510-2021-1-4-22$

Received 9.12.2020 